\title{
1. Delivering policy reform: making it happen, making it stick
}

\author{
Evert A. Lindquist and John Wanna
}

\section{The challenge}

Cascading and often unpredictable challenges continually confront the policy settings and policy frameworks of governments. They provide a constantly changing dynamic within which policy making operates. Sometimes these challenges are born of crises, sometimes of more systematic forces such as climate change or environmental threats. Some are the result of social and demographic trends, such as ageing or social inclusion. Sometimes they emerge by stealth, travelling under the radar until they suddenly manifest themselves. Such transformative changes are occurring across many fields simultaneously: technological, economic, international, defence and security related, environmental, social and demographic. They force governments to rethink what they do, when they do it and how they do it. Governments need constantly to re-examine and readjust their policy responses to align to the new challenges. But often the opportunity to respond in policy terms happens in very compressed time frames with inchoate ideas and incomplete information. That is the policy conundrum we increasingly face today.

Governments at all levels are asking their public services to identify innovative and workable reforms to address these challenges. Public service leaders around the world are struggling not only to better anticipate emerging demands but also to address reform backlogs. Time and time again, however, major policy reforms prove tough to become adopted in turbulent environments, and even tougher to anchor over time. This leads to considerable uncertainty and inefficiency as governments and societies try to keep pace with change and thrive. Policies that unravel are wasted opportunities and costly. They lead to cynicism about the effectiveness of governments and public service advice more generally, making it more difficult to deal with other emerging challenges.

This volume of essays on delivering policy reform offers an intriguing blend of strategic policy advice and management insight. It brings together a diverse range of top-level contributors from overseas as well as from Australia and New Zealand, including political leaders, public service executives, heads of independent agencies, and leading scholars. The contributors cover all levels of government. The purpose of this chapter is to provide a high-level guide and point of departure for sharing insight about particular cases, and to introduce the following key questions to be explored within the volume. 
- What are the challenges confronting governments and the societies they serve? How is this translating into demands on governments - often induced by crisis - for strategic policy reforms that move sectors in new directions and work in different ways?

- How can governments and public servants design and broker reform proposals and packages that are smart and feasible, with potential to address contemporary and emerging challenges in breakthrough and sustained (or durable) ways?

- How can governments and public servants configure and consolidate reforms so that, once adopted, they cannot be undermined by the forces that resist or corrode reform?

- How can policy makers perform adjustments in light of evidence and engagement during implementation without losing the integrity and momentum of the original reforms?

- How should public service leaders build the requisite capabilities to anticipate and analyse these challenges to provide useful policy advice and designs to governments? Indeed, how do they ensure that policy reforms are implemented reasonably intact?

These questions anchor our discussion.

\section{The new demands: challenges and expectations for effective policy reform}

The global financial crisis is only the latest challenge to confront governments around the world with a demand to respond quickly to stabilise a rapidly deteriorating situation and then follow up with new regulatory regimes and policy responses for the financial sector and to develop ways to regain control over public finances. We have only to think about the H1Nl flu epidemic, the 'mad cow' or BSE crisis, the equine flu outbreak, tropical cyclones, or the Asian financial crisis of the late 1990s - and many more that could be named - to see that these tipping-point challenges seem to be increasing. We tend to focus on dramatic crises, but we can also see similar slow-burning crises and demands for solutions emanating from challenges such as increases in national populations, significant demographic change in society, severe drought that lasts for years, and global climate change. This is not a passing spike in challenges on government radars, but increasingly should be seen as an ever-present reality that confronts governments at all levels, which creates significant demand for policy reform.

When we scratch below the surface of any of these challenges, we see that they are often a complex but disentangle-able mix of factors. They are not mono-causal. 
Complex change is the order of the day; governments are expected to provide suitable answers promptly. There are several implications flowing from this. Governments and public service leaders need better analytical skills and policy capacities. They need to design effective and workable policy reforms that address these challenges and maintain momentum as solutions are implemented. They need to ensure that these reforms actually stick, while striking a balance between ensuring that reforms are durable and that they are open to adaptation based on experience.

Recent international and national crises have demonstrated that, notwithstanding the litany of anti-government rhetoric permeating much of the public debate over the past few decades, citizens still expect governments to deal with or avoid crisis, and to identify policy reforms. Governments remain the community's insurer of last resort. It is also clear that the media, citizens and other stakeholders have high expectations about how well governments should implement policy reforms. Community disappointments are treated as policy failure. An inability to meet stated time lines and stay to budgets leads to the rapid corrosion of government credibility. On the political front, those actors who lose out in the policy process are increasingly prepared to undermine or undo policy reforms in the deliberative or legislative process and even after enactment. The big ' $\mathrm{P}$ ' and small ' $\mathrm{p}$ ' political struggle never ceases. Poor design and administration leave the door open for policy reversal. The stakes remain high after enactment, suggesting that implementing policy reforms requires strategic political and administrative mobilisation every bit as sophisticated and concerted as securing enactment.

The stakes are, thus, high for designing and implementing policy reform. Yet most governments typically tend to these issues only belatedly or haphazardly as a result of crisis. Australian governments, for example, have been prepared to announce public policies hastily without much thought to the implementation issues or the likely risks associated with the design and delivery. This is true of major announcements on such items as investments in water reform, pricemonitoring schemes, home-insulation programs, educational-performance standards and school ratings, and school facilities.

Another important part of their strategic arsenal is for public service institutions to improve their ability to anticipate and understand these challenges, and to envision a workable menu of policy options. Here public service leaders need to ensure that departments and agencies have good scanning capabilities, and that this information can be shared and considered across government and the community. Such information exchanges (and perspective contesting) are necessary to build the consensus for action and follow-through. The information gathered must be assessed for salience, risk, interconnectedness with other issues, and prioritising in terms of securing more data, and deeper 
analysis of trends, drivers, and outcomes. A critical issue concerns how public service leaders then test these assessments with political masters and with external experts and stakeholders, recognising that there might be sensitivities for governments' political agendas.

Engaging governments on the need for policy reform-let alone the merits of different kinds of interventions - is not simply a matter of sharing information. It is fundamentally about raising awareness, sharing dialogue and finding ways to persuade action. Busy, committed decision makers need compelling arguments and rigorous evidence, accompanied by feasible proposals for action and new policy frameworks. They need to develop their own narratives for reform and implementation that fit within broader narratives developed by the government. This engagement is a critical phase of policy reform, particularly when challenges are anticipatory as opposed to reactive in nature (for example, climate change and demographic change). How public service leaders engage governments will vary greatly according to ideological frames, time horizons, political and ministerial styles, the phase of the government's mandate (early, mid-stream, late), and by the nature of the issue. Governments must decide whether they have sufficient political capital and will to press forward with significant policy reform. What frames a government chooses to work with will greatly affect the options and strategies for securing enactment of the proposed reforms.

\section{Designing and enacting policy reforms}

Once a government commits to action - and regardless of the urgency of the challenge - there remains the detailed work of designing and securing approval of policy reform. While it has become commonplace to publicly characterise all of our contemporary challenges as 'wicked' - despite considerable variation in their character - the essence of the label is perhaps salient. Addressing most of the complex and demanding challenges we have in mind requires non-incremental reform (or comprehensive policy innovation, which can range from deep to shallow in terms of the extent of policy and institutional change envisioned), as well as tapping into expertise and authorities across public service institutions and often across levels of government and the non-government sectors.

There has emerged considerable research-based writing on how policy reforms come to be enacted by governments, particularly in fluid and often overly complex policy environments (Christensen and Laegreid 2001; Kingdon 1984). There has been a focus on serendipity and how 'policy entrepreneurs' position ideas and solutions to take advantage of 'policy windows' that might quickly open, allowing decisions to be taken, and then shut. For our purposes, the key 
takeaway from this perspective concerns the fact that advisors to governments must be ready with frames, evidence, and policy solutions; all of the players will have to work with what they have; there will not be time to undertake meaningful policy research on short notice. This perspective, however, understates the strategic and organisational capacity dimension of developing policy designs and ensuring enactment inside and outside government.

As noted above, policy reforms intended to address significant challenges necessarily involve working across the vertical boundaries of government and public service institutions. This requires identifying the implicated departments and agencies, assigning lead responsibility for assembling and coordinating the required technical and policy work, ensuring sufficient central oversight of this work, and linking it to political decision-making repertoires. Policy task forces or 'adhocracies' might need to be established for this purpose (Desveaux et al. 1994; Waterman 1992), requiring skilled leadership that can navigate the political, technical, policy, administrative, and external boundary-spanning aspects of policy development, and assemble a high-performing team in support.

An open question concerns the extent to which governments engaged in such coordinating capabilities will also engage key stakeholders and rely on broader public consultations (Huxham and Vangen 2008; Stewart 2009). The answer depends heavily on the nature of the issue, time pressures, the tactical posture of the government (does it seek to surprise?), the extent to which it has fleshed out its policy design and has developed an overarching narrative to support its intervention, and whether it is prepared to be flexible or negotiate. If governments have more time, or require the support and buy-in of other governments and non-governmental actors in order to proceed, external engagement on design issues becomes a relatively important feature of the process, requiring additional leadership and administrative capabilities. It is not merely about rushing policy into law.

Most of the above remarks point to considerations when designing any sort of significant policy reform or comprehensive intervention. But a critical focus of this volume concerns the extent to which designers - ministers and public service executives alike - thoroughly anticipate the political, policy and administrative challenges that await approved policies after enactment. Much like planning for transitions in government, do policy designers think carefully about who will take over once a policy has been formulated, approved and enacted? Have the ministers thought through who will take on custodial responsibility for overseeing the political aspects of implementation? How will the strategy of implementation (roll-out, phasing, stages) affect the integrity and durability of the reforms? Do new administrative capabilities have to be reconfigured? Are new leaders required in the Public Service to maintain momentum? Who will exercise stewardship for the policy reforms? 
Finally, it must be noted that policy reforms - no matter how open the processcan proceed iteratively, in fits and starts, both internally and externally. Indeed, this dynamic will likely stand as the most intriguing aspect to reflect on. The iterative process forms the constantly changing context in which evidence, arguments, and narratives are tested, challenged, and reformulated at the political and administrative levels. This often leads to new perspectives and approaches, and sometimes a call by governments for new policy-advising capabilities.

\section{Making reforms stick: design, durability, implementation}

It is one thing for governments to design and enact policy reforms, and quite another to ensure that they are fully implemented, particularly when dealing with complex challenges. Indeed, the origins of modern policy literatureseeking to understand the daunting challenges of implementation-were stimulated by overwhelming evidence of policy failure (Goggin et al. 1990; Hill and Hupe 2002; O'Toole 2004; Pressman and Wildavsky 1973). Much has been written on policy implementation from the perspectives of administration, collaboration and project management, but here we focus more on the politics and strategies for ensuring that reforms are more likely to succeed, even if they might be modified over time.

The implementation literature has long recognised that the success of even the best-designed policies depends considerably on the motivations and capabilities of those assigned to deliver the envisioned programs, which might include other governments and non-governmental actors, and the incentives of frontline staff, and whether the grain of the policy fully anticipates on-the-ground realities of service delivery (Barrett 2004; Huxham and Vangen 2008). This, in turn, has led to considerable interest in the ability of agencies administering reforms to collaborate and problem solve with other entities, and to mutually adjust in order to achieve the best possible results. While bottom-up and topdown perspectives on implementation have been explored extensively, this volume seeks instead to explore the extent to which and how these dynamicsalong with concerted efforts by affected stakeholders to roll back or undermine the policy during the implementation phase - are anticipated by governments as designers and overseers of reform.

Several questions arise here. One set of questions focuses on the robustness of the policy design. Did the policy design attempt to anticipate the political, administrative and inter-organisational challenges of implementation in a compelling way? Or was it, in fact, 'under-designed' and iterative, left open to 
reinterpretation and renegotiation? If the proposed implementation plan was under-funded because of resource constraints, have further risk assessments been made and the plan for implementation amended? If not, we invite failure or disappointments. If cabinets are prepared to cut the operational funds from programs, are they equally prepared to 'de-scale' the program and tailor policy to the resources they chose to allocate? Indeed, there are some who claim that up to 25 per cent of program funds should be left uncommitted to permit enhancement and adaptation in delivery. A narrow concern with prudence and parsimony of funds can significantly undermine the aspirations of even the bestdesigned policy - either at the outset or at some later date. Alternatively, under what conditions can 'under-design' at the outset end up being an advantage for subsequently anchoring reforms (as with careful piloting or the use of prototypes)?

There are related questions about the time frames or temporal character of different policy reforms. Do reforms have different gestation periods? How long does it take to anchor certain reforms, to get beyond critical points that might place their integrity at risk? Are we thinking in terms of a few months, a couple of years, or even across the mandate of different governments? What political and strategic protection and guidance are required during the implementation phase? Where are the immediate 'big risks', the short-term critical moments, and how are these to be managed?

In the United States, Eric Patashnik (2008) has previously emphasised that successful policy reforms are durable when they are supported by some new configuration of interests. He argues that in the United States new constituencies emerge or existing ones become strengthened to fight for various policies enacted by Congress. They coalesce to promote change and defend the new policy regime rather than seeking to undermine its very foundations. Consequently, former stakeholders favoured under the previous regime tend to decline in strength. An interesting question for contributors to this volume is whether the emergence of new configurations of interests around reforms is merely left to chance, or whether this is something that is assiduously cultivated during the implementation phase through information and communication strategies, proactive promotion, consultative and deliberative forums and access to decision makers, and whether compensating interests are negatively impacted by the reforms.

Finally, governments tend to be more interested in designing and announcing new policies, then moving on. Typically they have no shortage of other policy challenges to address, which in turn suggests that they have less time and incentive to oversee implementation adequately. To what extent, then, are governments and public-sector leaders prepared to implement reforms as concertedly as enacting them? Once the policy is adopted, does a new set of 
reformers (political and public service leaders) take over? Are new champions found or appointed in the knowledge that a different skill set will be required to ensure that the reforms are anchored? And again, are there critical moments and phases during implementation when the integrity of the reform is at risk?

\section{Making reforms last: from consolidation to adaptation and learning}

Ensuring that much-needed policy reforms are supported and durable is a laudable goal, but one that is often left to the political realm alone (to ministers, parties and government advisers). But it need not be consigned purely to this realm. Public services have a role in explaining policy publicly and to stakeholders - and possibly even assisting with the government's narrative. This is not an improper role. It provides a new governance platform to deal with continual change and emergent risk. We also know, however, that policy reforms cannot anticipate all factors and contingencies; there will inevitably be a great deal of learning and adjustment in order to meet these realities. The issues at stake here concern managing the tensions between seeking durability in policy reforms and making improvements or adjustments in light of feedback from those responsible for implementation and evidence on the performance of the policy and programs without losing the integrity and momentum of the original reforms.

One way to think about this might be to consider what the critical point for securing a policy reform might be, as well as the pace of change in the policy environment. Once a point of no return has been reached, it might be easier to debate and adapt the policy reform. The earlier such debate and adjustments might be required, the more there is a risk that such deliberations will provide an opportunity for interests resisting the reforms to undermine the policy regime. This risk increases to the extent that the announced policy reform was directional and meant to be elaborated through negotiation and implementation.

This raises the question of how governments and public service leaders can structure time-monitoring and feedback processes so as to usefully identify and inform needed adjustments, which might be significant, without creating a political opportunity to undermine the reform itself. There might also be a symbolic dimension to this, where governments declare that the first phase of implementation has been completed, thus opening up the opportunity to refresh the policy in operational terms. Examples of where this feedback has worked well include: income-contingent loans for higher education and perhaps vocational education (tax-deferred schemes for tuition), Landcare programs for environmental sustainability, and prudential regulation of the financial 
sector. Alternatively, examples of where it has not worked well include: urban sprawl and a lack of public housing provision, poor transport integration, and significant deficiencies in aged care. Finally, we have to recognise that, under some circumstances, announced reforms might have been misguided, unworkable, or no longer relevant, and deserve to be terminated or significantly rethought.

\section{Delivering policy reform: implications for public service institutions}

In assembling this volume of essays, we commenced with a generic approach, tapping into international literature about improving policy design and implementation. A review of diverse Organisation for Economic Cooperation and Development (OECD) countries together with some prescient OECD publications shows that the themes of keeping pace with change and developing effective policy reforms are a concern of governments around the world. With this context in mind, we invited contributors to consider the distinctive challenges and opportunities that Australian and New Zealand governments have faced when designing reforms and attempting to make them stick. While much of the attention is on how governments have selected, designed and implemented reforms, it is also important to remember that other actors are caught up in the change processes, becoming participants or collaborators in the reform endeavours - such as other levels of government, business and farmers, road users, the community and non-governmental delivery partners.

This volume of essays commences by thinking broadly about the demands on governments to recognise and address policy challenges, especially after the turbulence of the recent past and the after-effects of the global financial crisis. Part 2 then explores national reform initiatives in Australia and New Zealand. Here the emphasis is on learning from successful attempts to implement national strategies of reform, showing how policy makers and their advisers designed and delivered more durable policy reforms often in the face of opposition. In Part 3 the attention turns to specific sectoral reform initiatives where policy makers were concerned to change community or organisational behaviour to improve social outcomes. The ultimate goal in each of these cases is to explore how those of us today engaged with public service institutions can be better prepared to meet these advising and implementation challenges - a crucial point to which Paul 't Hart returns with his 'rules for reformers' in Chapter 17.

Given the premise that governments should anticipate key challenges and seek to put in place durable policy reforms, this might change how we view the sort of capabilities that public service institutions should develop. Many 
governments at the federal, state and local levels have been having precisely this conversation about building new sets of capabilities in recent years (see, for example, the recent Moran Review of the Australian Public Service: AGRAGA 2010; and Lindquist 2010). We suggest that one way to approach this enormous topic is to revisit the different phases of policy reform, and to recognise that invoking the term 'durability' should not mean simply adding a throwaway adjective to policy reform. Rather, it involves setting a new standard for quality in design and implementation, and thus that analytical traction can be gained by looking for associated trade-offs. Consequently, the following suggestions could be considered.

- To achieve policy durability in the longer term might require far more research and front-end analysis, and more political and public service executive involvement during the implementation phase. In turn this implies that we need to scan emerging challenges and ascertain how one aspect of policy reform might fit in with or be traded off against other government priorities. But scanning, scenario developing and the selection of preferred options can take time and be administratively precarious. Policy analysts have to secure ministerial, executive and stakeholder buy-in so that the fruits of their labours are not wasted. Alternatively, where policy is more iterative and emergent - or even 'garbage-can'-like in its initiation - there will still be a need to adapt policy parameters strategically to continually align with the changing environment and to anticipate future changes.

- Recognising the need to make policy reforms more durable often requires more thorough testing and strategising of proposed policy designs at the outset. This requires more resources, acknowledging that implementation is not simply project management, and recognising that if ex ante engagement of interests is not possible, alternative and credible ways must be found to anticipate the reactions and needs of affected interests and citizens. Many problems with policies are practically discovered in the processes of implementation rather than anticipated and averted beforehand. Where it is not possible to pre-test, we might be able to devise better monitoring of the consequences of the policy in operation and make iterative changes.

- Implementing durable policy reforms requires robust evaluation, both inside the executive and in public. Public service leaders should persuade governments to undertake effective policy and program evaluation internally as a way of monitoring progress and recalibrating performance. Both ministers and senior executives need to pay closer attention to the evaluation of results of proposed reforms. Parliaments and other scrutiny actors need to become more assertive in requiring and undertaking performance evaluations as part of their overview. Many reforms will require shared evaluations with other governments and non-governmental partners to gauge the effectiveness 
of the changes. These suggestions are applicable whether the policy in question is planned and rationalistic or opportunistic and contingent. They also suggest that the Public Service must be able to marshal good evidence and have sophisticated and credible data on tap. They will also need good prudential judgment and the capabilities to assess the meaning of evaluative data, and be able to productively engage with societal interests and citizens over the findings. Ideally, ministers and senior public servants should be able to develop credible narratives recognising what has been accomplished and the need for subsequent policy adjustments.

Undoubtedly, there are other ideas to improve policy reception that arise in the remainder of this volume. But, standing back and looking across the panoply of government responsibilities and the thorny and novel character of the many challenges that political leaders must address, we observe that creating durable policy reforms is invariably a creative and emergent process in all phases. It requires anticipation, contingency planning, considerable prudential judgment and strategic leadership. Put another way, for us to realise the ambition of creating durable policy reform requires vision, verve, no small amount of energy, some luck, and a degree of comfort with what Robert Quinn has described as 'building the bridge as you walk on it'. Going forward, the question that emerges now is how can the requisite mental frames for taking on these challenges be developed as we groom public service talent for the future; how will tomorrow's policy makers and administrators acquire the necessary capacities to be able to manage effectively in a more complex and changing environment?

\section{References}

Advisory Group on Reform of Australian Government Administration (AGRAGA) 2010, Ahead of the Game: Blueprint for reform of Australian government administration, March, Commonwealth of Australia, Canberra.

Barrett, S. 2004, 'Implementation studies: time for a revival?, Public Administration, vol. 82, no. 2.

Christensen, T. and Laegreid, P. 2001, 'Transforming governance in the new millennium', in T. Christensen and P. Laegreid (eds), New Public Management: The transformation of ideas and practice, Ashgate, Aldershot, UK.

Desveaux, J., Lindquist, E. A. and Toner, G. 1994, 'Organising for policy innovation', Canadian Journal of Political Science, vol. 28, no. 3 (September).

Goggin, M., Bowman, A., Lester, J. and O'Toole, L. 1990, Implementation Theory and Practice, Harper Collins, New York. 
Delivering Policy Reform

Hill, M. and Hupe, P. 2002, Implementing Public Policy, Sage, London.

Huxham, C. and Vangen, S. 2008, 'Doing things collaboratively: realising the advantage or succumbing to inertia?', in J. O'Flynn and J. Wanna (eds), Collaborative Governance: A new era of public policy in Australia?, ANU E Press, Canberra.

Kingdon, J. 1984, Agendas, Alternatives and Public Policies, Little-Brown, Boston.

Lindquist, E. A. 2010, 'From rhetoric to blueprint: the Moran Review as a concerted, comprehensive and emergent strategy for public sector reform', Australian Journal of Public Administration, vol. 69, no. 2 (June).

O'Toole, L. 2004, 'The theory-practice issue in policy implementation research', Public Administration, vol. 82, no. 2.

Patashnik, E. M. 2008, Reforms at Risk: What happens after major policy changes are enacted, Princeton University Press, Princeton, NJ.

Pressman, J. and Wildavsky, A. 1973, Implementation: How great expectations in Washington are dashed in Oakland, University of California Press, Berkeley.

Stewart, J. 2009, The Dilemmas of Engagement: The role of consultation in governance, ANU E Press, Canberra.

Waterman, R. H. 1992, Adhocracy, Norton, New York. 